\title{
The Macroeconomic Effect of Shadow Credit Market Financing
}

\author{
Li Jianjun ${ }^{1}$, Han Xun ${ }^{1}$ \\ ${ }^{1}$ School of Economics and Finance, Central University of Finance and Economics, Beijing, China. \\ Correspondence: Han Xun, School of Economics and Finance, Central University of Finance and Economics, Beijing, \\ China.
}

Received: April 5, 2016

Accepted: April 29, 2016

Available online: May 3, 2016

doi:10.11114/aef.v3i3.1587

URL: http://dx.doi.org/10.11114/aef.v3i3.1587

\begin{abstract}
Shadow credit market is a credit creation market which is parallel to the bank credit market. It has the function of credit creation, liquidity conversion and maturity transformation. In this paper, based on the different participants of shadow credit market, we divides it to the dealer, formal financial institution and private lending credit markets and measures the scale of shadow credit market. Based on the monthly data from year 2006 to 2014, by constructing VAR model, the paper attempts to analyze the macroeconomic effect of the shadow credit market financing. The research results show, firstly, shadow credit market as a way of resource allocation, has certain positive effect in meeting the needs of social investment and financing and promoting economic growth. Secondly, shadow credit market has changed the traditional money supply model and transmission mechanism of monetary policy, expanding the money supply and weakening the effectiveness of monetary policy. Thirdly, the shadow credit market impact the price level through influencing credit market scale and money supply.
\end{abstract}

Keywords: shadow credit market, monetary policy, non-observed revenue, macroeconomic effect

\section{Introduction}

After the 2008 economic crisis, the Chinese government launched the 4 trillion economic stimulus plan, bank credit scale expanded rapidly. In promoting economic growth at the same time, also led to asset price bubbles and high inflation pressure brought by the expansion of credit. So since 2010, China's financial authorities began tightening credit. Bank credit crunch promoted the development of the shadow credit market. On the one hand, traditional financial institutions in the face of the low lever pressure began to innovate, bank financial products, money market funds scale expanded rapidly; on the other hand, private lending enterprises arose under the condition of money supply and demand unbalance, providing funds for capital demanders to make up money supply and demand gap. In recent years, China's shadow credit market is developing rapidly. From 2006 to 2014, social financing scale increased from 4.2696 trillion yuan to 16.4133 trillion yuan, but RMB loans accounted for the proportion of social financing scale decreased from $73.83 \%$ to $59.59 \%$. Shadow credit market have characteristics of credit creation ability and is basically not effected by national economic policy adjustment. Therefore, strengthen the supervision of the shadow credit market, build effective macro regulatory become a top priority of China regulatory authorities.

Shadow credit market is outside the banking supervision, providing liquidity to the market. Shadow credit market, as the supplement of traditional credit market, is also a means of resource allocation. Shadow credit market has the functions of credit creation, liquidity conversion and maturity transformation, it has impact on economic growth, price level and money supply. The final product and service value created by small and medium-sized enterprises account for $60 \%$ in gross domestic product which means small and medium enterprises play an important role in increasing employment, but the traditional commercial banks exist serious problem of credit rationing which makes it hard for small and medium-sized enterprises to obtain financing from the traditional credit market, shadow credit market provides a good financing environment, promoting economic growth. Compared with commercial bank loans, the special lending mechanism of shadow credit market has also led to greater market risk. Therefore, shadow credit market is a "double-edged sword" role to economic development. On the one hand, its flexible refinancing function can alleviate the financing difficulties of small and medium-sized enterprises. On the other hand, once encountered economic recession or counterparty risk problems, the transfer of risk and the negative impact on the economy would probably be more severe.

The development of shadow credit market will also affect the central bank's monetary policy. The influence of shadow 
credit market on monetary policy reacts in two aspects. First, the existence of shadow credit market has changed the monetary policy transmission mechanism, making the central bank monetary control policy cannot pass into the real economy as expectation, the effect of monetary policy will be limited. Second, shadow credit market as the supplement of traditional credit market has changed the traditional monetary supply model, thus affect the money supply. Especially after 2008, shadow credit market develop rapidly, its characteristics of opaque market transaction, high risk relevance and weak internal regulation, making measure the scale accurately and explore the macroeconomic effect of shadow credit market financing have an important significance in strengthening the effectiveness of monetary policy and improving the macroeconomic stability.

In the process of research, based on the different participants of shadow credit market, we divided it to the dealer, formal financial institution and private lending credit market. Measure shadow credit market scale from 2006 to 2014 respectively and construct VAR model to analyze the macroeconomic effect of shadow credit market financing on economic growth, price level and monetary policy.

\section{Measurement of shadow credit market scale}

\subsection{Definition of credit market}

Shadow credit market is a lending market, small loan company, pawnshops, P2P, network finance company, chamber of commerce,ect are credit suppliers, small and medium-sized enterprises, individual businesses, framers and natural person, ect are capital demanders ${ }^{[1]}$. The biggest difference between the shadow credit market and the traditional lending market is the participant. The participant of the traditional credit market is commercial bank, it provide liquidity to the market through issuing loans. The participants of the shadow credit market are divided into three categories, the first type is dealer market, credit market products contain government support agency bonds, commercial paper, super commercial paper, collective enterprise bonds, small and medium-sized enterprise collective notes, medium-term notes, asset-backed securities, asset-backed paper and money market funds, ect. The second type is formal financial institution, mainly operate bank financing, trust financial products, securities company financial products , insurance company financial products and financial leasing business. The third type is private lending market. Participants mainly conclude small loan company, private capital management company, pawnshop, P2P, crowdfunding company, internet finance company, ect.

Shadow credit market tools may be loan contract, may also be other debt instruments, such as entrust investment agreement and financial agreement. Shadow credit market has the function of credit creation, but the central bank is hard to regulate it using monetary policy tools. The development of the shadow credit market is driven mainly by two factors. First, national bank have serious credit rationing problem, financing demand of small and medium-sized enterprises is difficult to be satisfied by traditional credit market. Under the condition of bank credit quota restrictions and bond market strong external financing constraints, small and medium-sized enterprises can obtain financing from shadow credit market. Second, under the external environment of financial innovation, market competition and lack of supervision, the traditional institution are gradually involved in the shadow credit market.

\subsection{Measurement of shadow credit market}

At present, some domestic and foreign literature put forward measuring method of the scale of shadow banking system, but there is still no perfect and standard measuring system. The measurement of shadow credit market should not only estimate the scale of the shadow banking system, but also estimate the scale of private lending. However, private lending is mostly underground, strong concealment, so the measurement data of this part is hard to obtain. Pei ping and Yin Wen ${ }^{[2]}$ summed new entrusted loans, trust loans, no discount bank acceptance bill and corporate bond holdings to estimate the scale of shadow banking credit creation increment. Zhang Shiqiang (2013) aggregated credit scale of bank financial products, entrusted loans, trust loans, small loan companies, private equity funds and pawnshops to estimate the scale of shadow banking system ${ }^{[3]}$.

In this paper, based on the different participants of shadow credit market, we divide it to the dealer, formal financial institution and private lending credit market, and measure the scale of shadow credit market. The dealer shadow credit market is the market shadow credit market, mainly include super commercial paper, commercial paper, medium-term notes, government support agency bonds, small and medium-sized enterprise collective debt, asset-backed paper and asset-backed securities. The shadow credit market scale of formal financial institution can be estimated from capital source and fund operation angles. From the perspective of funding source, mainly contain bank financing and trust; from the perspective of funding operation, mainly contain entrusted loans, trust loans and no discount bills. Private lending shadow credit market conclude two kinds of participants, one kind include small loan companies, pawnshops, financing guarantee companies and private equity firms, this kind of participants is not licensed and insufficiently regulation. Another kind is private lending institutions, containing P2P companies, internet finance company, crowdfunding, chamber of commerce, private bank. This type of participants is not licensed and without supervision. 
Because the private lending has extremely strong concealment, data are difficult to measure from the microscopic view, so this paper use the method of Li Jianjun(2008) non-observed finance to estimate the scale of private lending shadow credit market $^{[4]}$.

Measurement of scale of private lending credit market rely on the non-observed economy scale. Non-observed economy scale is economic output achieved by the capital poured by quasi financial institutions, not by bank, security companies and other traditional financial institutions. It refers to the production activities that should be included in the national economic accounting, but have not been accounted by the national economic accounting system. Non-observed economy scale can be reflected by non-observed revenue. Although non-observed revenue is hidden, but it will perform in the fund occupation of consumption, investment, net export and monetary saving in the end. From the point of spending, GDP is constituted by consumption (CUM), capital formation (CAF) and net exports (NEX). GDP add net foreign initial distribution (NFI) is gross national product (GNP). Gross national product (GNP) add net foreign often transfer income (NFT) is national disposable income (KNI), have the following corresponding relation.

$$
\begin{gathered}
\mathrm{GDP}=\mathrm{CUM}+\mathrm{CAF}+\mathrm{NEX} \\
\mathrm{GNP}=\mathrm{GDP}+\mathrm{NFI}=\mathrm{CUM}+\mathrm{CAF}+\mathrm{NEX}+\mathrm{NFI} \\
\mathrm{KNI}=\mathrm{GNP}+\mathrm{NFT}=\mathrm{CUM}+\mathrm{CAF}+\mathrm{NEX}+\mathrm{NFI}+\mathrm{NFT}
\end{gathered}
$$

The balance of payments account records regular economic transactions between domestic residents and non-residents. Credit records economic transaction activity of capital inflow, debit records the economic transaction activity of capital outflow. So the current-account balance $\left(\mathrm{CU}_{\mathrm{BOP}}\right)$ calculation formula is as follows:

$$
\begin{aligned}
& \mathrm{CU}_{\mathrm{BOP}}=\mathrm{NEX}+\mathrm{NFT}+\mathrm{NFI} \\
& \mathrm{KNI}=\mathrm{CUM}+\mathrm{CAF}+\mathrm{CU}_{\mathrm{BOP}}
\end{aligned}
$$

National saving (NS) is national disposal income deduct consumption, namely

$$
\text { NS=KNI-CUM }
$$

In a closed economy, national savings plus net capital transfer (NCT), excluding capital formation (CAF) is monetary savings (MS). But in an open economy, the domestic monetary savings may outflow, including foreign direct investment, securities investment and other investment. The net difference between the inflow of external savings and outflow of national savings is net external savings, is also financial account balance (FAвор).

$$
\begin{gathered}
\mathrm{MS}=\mathrm{CU}_{\mathrm{BOP}}+\mathrm{NCT} \\
\mathrm{MS}=\mathrm{KNI}-\mathrm{CUM}+\mathrm{NCT}-\mathrm{CAF}+\mathrm{NFS}
\end{gathered}
$$

Therefore, the increase or decrease quantity of a country's cash and deposit is different from monetary savings, so exist non-observed finance and non-observed revenue.

$$
\begin{gathered}
\mathrm{NOE}=\Delta \mathrm{C}+\Delta \mathrm{D}-\mathrm{MS} \\
\mathrm{NOE}=\Delta \mathrm{C}+\Delta \mathrm{D}-\mathrm{KNI}+\mathrm{CUM}-\mathrm{NCT}+\mathrm{CAF}-\mathrm{NFS}
\end{gathered}
$$

On the basis of non-observed revenue, we can measure the scale of private lending, because the scale of non-observed loan has close relationship with non-observed revenue. As a result, we assume the loan support ratio of non-observed economic activities is the same with the economic activity which can be calculated. Based on bank loans, non-observed revenue and gross domestic product can estimated the scale of private lending from 1982 to 2014.

$$
N O L=\frac{N O E}{G D P} \times L
$$

Table 1, 2, and 3 respectively measure the scale of dealer, formal financial institution and private lending credit market. Table 4 aggregate three kinds of shadow credit market to calculate the scale of shadow credit market. We can see from table 1 that there is an upward trend in the scale of dealer credit market year by year, commercial paper, medium-term notes, government support securities have lager contribution to the expansion of scale of dealer credit market, super commercial paper and asset-backed securities expand rapidly. The scale of formal financial institution credit market is shown in table 2, from perspective of funding source, the size of non-guaranteed bank financial products increase from 530 billion to 15.02 trillion yuan, trust products increase from 71.137 to 1587.529 billion yuan from 2007 to 2014, Therefore, from the perspective of funding source, the scale of formal financial institution credit market is rising. From the perspective of capital operation, the size of entrusted loans, trust loans and no discount bills show a general ascending trend except a slight decline in 2014. Table 3 shows that scale of private lending has a significant upward tendency, the scale of private lending is at round 32.74 billion yuan in 1982 and rise to 12801.78 billion yuan in 2014 . We obtain the scale of shadow credit market by aggregating the scale of three types of credit market. From table 4, we can see from 2007 to 2014, the scale of shadow credit market rise from 4212.919 billion yuan to 22094.698 billion yuan, in 7 years, the scale of shadow credit market expand 5 times. It is thus obvious that shadow credit market has been an 
important part of the credit market, and in the continuous development.

Table1.The scale of dealer shadow credit market

\begin{tabular}{ccccccccc}
\hline year & SCP & CP & $\begin{array}{c}\text { medium-term } \\
\text { notes }\end{array}$ & $\begin{array}{c}\text { government } \\
\text { support } \\
\text { agency bonds }\end{array}$ & $\begin{array}{c}\text { enterprise } \\
\text { collective } \\
\text { debt }\end{array}$ & $\begin{array}{c}\text { enterprise } \\
\text { collective } \\
\text { notes }\end{array}$ & ABN & ABS \\
\hline 2007 & 0 & 3203.10 & 0 & 0 & 0 & 0 & 0 & 324.05 \\
2008 & 0 & 4203.10 & 1672 & 0 & 0 & 0 & 0 & 551.06 \\
2009 & 0 & 4561.05 & 8622 & 0 & 0 & 12.65 & 0 & 398.58 \\
2010 & 0 & 6530.35 & 13536 & 1090 & 20.98 & 55.12 & 0 & 182.32 \\
2011 & 0 & 5023.50 & 19742.7 & 1090 & 35.16 & 93.68 & 0 & 95.27 \\
2012 & 3531 & 8326.97 & 24922 & 1090 & 34.82 & 187.66 & 57 & 268.90 \\
2013 & 4729 & 8244.20 & 28839.5 & 10050 & 32.99 & 190.83 & 97.8 & 354.27 \\
2014 & 6999.5 & 10365.90 & 31783.1 & 11675 & 83.67 & 142.49 & 171.4 & 2751.14 \\
\hline
\end{tabular}

Data source: Shang Hai clearing house、China Central Depository and Clearing Corporation unit: hundred million yuan

Table 2. The scale of formal financial institution shadow credit market

\begin{tabular}{cccccr}
\hline & \multicolumn{2}{c}{ Capital source } & \multicolumn{3}{c}{ Capital operation } \\
Year & $\begin{array}{c}\text { Non-guaranteed bank } \\
\text { financial products }\end{array}$ & $\begin{array}{l}\text { Trust } \\
\text { products }\end{array}$ & $\begin{array}{c}\text { Entrusted } \\
\text { loans }\end{array}$ & $\begin{array}{c}\text { Trust } \\
\text { loans }\end{array}$ & $\begin{array}{c}\text { No discount } \\
\text { bills }\end{array}$ \\
2007 & 5300 & 711.37 & 1702 & 3371 & 6701 \\
2008 & 8700 & 1115.87 & 3144 & 4262 & 1064 \\
2009 & 17000 & 1663.86 & 4364 & 6780 & 4606 \\
2010 & 28000 & 3607.36 & 3865 & 8748 & 23346 \\
2011 & 45900 & 8470.04 & 2034 & 12962 & 10271 \\
2012 & 71000 & 12499.29 & 12845 & 12838 & 10499 \\
2013 & 102100 & 13869.64 & 18404 & 25466 & 7755 \\
2014 & 150200 & 15875.29 & 5174 & 25069 & -1286 \\
\hline
\end{tabular}

Data source: wind database unit: hundred million yuan

Table 3. The scale of private lending shadow credit market

\begin{tabular}{|c|c|c|c|c|c|c|}
\hline year & GDPi & KNI & NOE & NOE/GDP & $\mathrm{L}$ & NOL \\
\hline 1982 & 5323.4 & 5339.7 & 548.0 & $10.30 \%$ & 3180.6 & 327.4 \\
\hline 1983 & 5962.7 & 5995.7 & 692.0 & $11.61 \%$ & 3589.9 & 416.6 \\
\hline 1984 & 7208.1 & 7254.0 & 1195.4 & $16.58 \%$ & 4766.1 & 790.4 \\
\hline 1985 & 9016.0 & 9047.9 & 1233.0 & $13.68 \%$ & 5905.6 & 807.6 \\
\hline 1986 & 10275.2 & 10287.4 & 1833.3 & $17.84 \%$ & 7590.8 & 1354.3 \\
\hline 1987 & 12058.6 & 12059.0 & 1824.7 & $15.13 \%$ & 9032.5 & 1366.8 \\
\hline 1988 & 15042.8 & 15052.4 & 2271.6 & $15.10 \%$ & 10551.3 & 1593.3 \\
\hline 1989 & 16992.3 & 17015.3 & 2443.7 & $14.38 \%$ & 14306.1 & 2057.4 \\
\hline 1990 & 18667.8 & 18731.4 & 3477.2 & $18.63 \%$ & 17680.7 & 3293.3 \\
\hline 1991 & 21781.5 & 21870.4 & 4261.7 & $19.57 \%$ & 21337.8 & 4174.9 \\
\hline 1992 & 26923.5 & 27001.0 & 6850.2 & $25.44 \%$ & 26322.9 & 6697.4 \\
\hline 1993 & 35333.9 & 35327.6 & 8624.5 & $24.41 \%$ & 32943.1 & 8041.0 \\
\hline 1994 & 48197.9 & 48223.7 & 10845.5 & $22.50 \%$ & 39976 & 8995.4 \\
\hline 1995 & 60793.7 & 59930.3 & 13034.4 & $21.44 \%$ & 50544.1 & 10836.9 \\
\hline 1996 & 71176.6 & 70319.5 & 14691.7 & $20.64 \%$ & 61156.6 & 12623.5 \\
\hline 1997 & 78973.0 & 78079.5 & 13295.5 & $16.84 \%$ & 74914.1 & 12612.2 \\
\hline 1998 & 84402.3 & 83378.5 & 14381.2 & $17.04 \%$ & 86524.1 & 14742.8 \\
\hline 1999 & 89677.1 & 88598.2 & 14689.1 & $16.38 \%$ & 93734.3 & 15353.6 \\
\hline 2000 & 99214.6 & 98522.8 & 13899.6 & $14.01 \%$ & 99371.1 & 13921.5 \\
\hline 2001 & 109655.2 & 108771.1 & 15902.8 & $14.50 \%$ & 112314.7 & 16288.5 \\
\hline 2002 & 120332.7 & 120170.4 & 23427.8 & $19.47 \%$ & 139802.9 & 27218.5 \\
\hline 2003 & 135822.8 & 136436.5 & 32454.0 & $23.89 \%$ & 169771 & 40565.8 \\
\hline 2004 & 159878.3 & 161348.8 & 21304.1 & $13.33 \%$ & 188565.6 & 25126.8 \\
\hline 2005 & 184937.4 & 185696.9 & 35008.6 & $18.93 \%$ & 206838.5 & 39154.5 \\
\hline 2006 & 216314.3 & 218232.0 & 38658.4 & $17.87 \%$ & 238279.8 & 42583.9 \\
\hline 2007 & 265810.3 & 269362.3 & 25675.1 & $9.66 \%$ & 277746.5 & 26828.0 \\
\hline
\end{tabular}




\begin{tabular}{rrrrrrr}
\hline 2008 & 314045.4 & 319211.1 & 46721.6 & $14.88 \%$ & 320048.7 & 47614.7 \\
2009 & 340902.8 & 342478.1 & 110439.0 & $32.40 \%$ & 425596.6 & 137876.5 \\
2010 & 401512.8 & 402458.2 & 81870.5 & $20.39 \%$ & 509223 & 103833.2 \\
2011 & 473104.1 & 469676.8 & 99544.5 & $21.04 \%$ & 581892.5 & 122434.3 \\
2012 & 519410.1 & 518379.7 & 121251.6 & $23.34 \%$ & 629909.4 & 147046.7 \\
2013 & 588018.7 & 582656.7 & 102787.7 & $17.48 \%$ & 766326.64 & 133956.6 \\
2014 & 636138.8 & 632175.8 & 93835.8 & $14.75 \%$ & 867867.89 & 128017.8 \\
\hline
\end{tabular}

Data source: National statistics yearbook unit: hundred million yuan

Table 4 .The scale of shadow credit market

\begin{tabular}{lcccc}
\hline year & dealer & Formal financial institution & Private & Shadow credit market \\
2007 & 3527.15 & 11774.00 & 26828.0 & 42129.19 \\
2008 & 6426.16 & 8470.00 & 47614.7 & 62510.87 \\
2009 & 13594.28 & 15750.00 & 137876.5 & 167220.74 \\
2010 & 21414.77 & 35959.00 & 103833.2 & 161206.96 \\
2011 & 26080.31 & 25267.00 & 122434.3 & 173781.61 \\
2012 & 38418.35 & 36182.00 & 147046.7 & 221647.01 \\
2013 & 52538.59 & 51625.00 & 133956.6 & 238120.16 \\
2014 & 63972.20 & 28957.00 & 128017.8 & 220946.98 \\
\hline
\end{tabular}

Data source: Shang Hai clearing house、 National statistics yearbook 、 author calculate unit: hundred million yuan

\section{The generation mechanism of macroeconomic effect of shadow credit market financing}

\subsection{The effect of shadow credit market financing on national economic growth}

China has existed bank credit rationing problem for a long term, formal financial institutions have serious credit discrimination. Especially since 2010, China's financial authorities began further credit tightening. At this time, shadow credit market appeared to provide liquidity to small and medium-sized enterprises, eased the problem of the bankruptcy of small and medium-sized enterprises due to liquidity shortage. Shadow credit market and traditional credit market both have the function of credit creation, liquidity conversion, maturity transformation, and can improve the efficiency of resource allocation. But shadow credit market has the characteristics of high leverage, complicated product structure, opaque market transactions and lack of regulation which will increase the vulnerability of financial system and macroeconomic volatility. Liu Rongmao, Jiang Yi found that shadow banking system has significant influence on economic growth and price stability ${ }^{[5]}$. Shen Yue(2013) used macro fund flow analysis to estimate the scale of shadow banking system and found there is only one-way causal relationship between the scale of shadow banking system and economic growth, economic growth will stimulate the expansion of shadow banking system, but on the contrary, the promoting effect of shadow banking system on economic growth is not significant ${ }^{[6]}$.Rydstrom(2007) pointed that shadow banking system is a typical financial innovation induced by bank off-balance-sheet activities, and has played an active role in the development of entity economy ${ }^{[7]}$.Gennaioli(2011) argued that banks can bring the improvement of benefits, but when investors ignore tail risk, risk loans will appear vulnerability and liquidity risk ${ }^{[8]}$.

Therefore, the development of shadow credit market is a "double-edged sword". On the one hand, the development of shadow credit market is conductive to economic growth, it can make up the traditional lending market liquidity shortage. When commercial banks can't satisfy the market financing demand because risk and return doesn't match or external regulatory restrictions, shadow credit market can relieve the market environment of currency supply and demand imbalance through innovative products and risk diversification arrangements. On the other hand, shadow credit market may trigger financial risks. Shadow credit market products have the characteristics of high leverage, implement assets and liabilities management based on the value of risk. So, in the case of falling asset value, shadow credit market have to deleverage. The price of the risky assets will decline with institutional investors selling assets, causing financial market turbulence and liquidity squeeze, even lead to market credit crisis. Turmoil in the financial markets will also inevitably lead to economic recession, having a negative effect on the financial system and macroeconomic stability. Moreover, the development of shadow credit market may aggravate industry hollowing problem, and hit the real economy. Since the borrowing cost and risk of shadow credit market is higher than traditional credit market, some large enterprises can obtain low interest loans from the traditional credit market, then transfer capital to fund demanders though shadow credit market to earn interest margin. This risk-free arbitrage will make enterprise invest more energy and capital in private lending and gradually divorce from the entity industry. Therefore, the influence of shadow credit 
market on the economic growth is reflected in two aspects. On the one hand, its flexible refinancing function can promote the development of small and medium-sized enterprises, and improve the efficiency of capital allocation. On the other hand, when economy is suffering from systemic risk, the negative impact of the transfer of risk on the economy also shouldn't be ignored.

\subsection{The effect of shadow credit market financing on price level}

Price level is one of the most important observation variables, it reflects the relationship between total supply and total demand, mainly affected by credit and money supply changes. The goal of the government in the formulation of macroeconomic policy is not only to realize economic growth, more to maintain price stability. When effective demand is lower than the effective supply, price will decline, at this point, expand credit will increase total social investment level and total demand, price level will increase until it reaches an equilibrium level. When the actual economic operation level exceeds potential supply capacity of the national economy, price will rise because demand relative to supply is too high. At this time, reduce credit scale will help to reduce social demand level, price level will decline until it reaches an equilibrium state of aggregate demand equals aggregate supply. Therefore, the scale of shadow credit market will have certain disturbance on the price level though influencing the social credit scale.

\subsection{The effect of shadow credit market financing on monetary policy}

Shadow credit market has positive effect on China's financial deepening and solving the small and medium-sized enterprise financing difficulties. Shadow credit market expand rapidly and its operation mode of independent of monetary policy system has great influence on the credit market. Wang Zengwu(2010) ${ }^{[9]}$ has discussed the effect of shadow banking system on money supply taking commercial bank financial products as an example, and put forward that shadow banking system make money supply will be much higher than credit ceiling set by the central bank, interfering central bank monetary policy objectives. The study of Gertler and Kiyotaki(2010) found that non-bank financial institutions have function of amplification effects in the conduction process of macroeconomic shocks ${ }^{[10]}$. Andrew Sheng used a large number of data to prove that shadow banking system has an amplified effect on money supply ${ }^{[11]}$. The effect of shadow credit market on monetary policy mainly lies in two aspects. On the one hand, shadow credit market has the function of credit creation, it has increased the supply of credit, and expanded the money supply. On the other hand, shadow credit market has impact on monetary policy transmission mechanism, the traditional monetary policy transmission mechanism is weakened and distorted, thus affecting the effectiveness of monetary policy, increasing the difficulty of central bank monetary operation mechanism.

Shadow credit market as the supplement of the traditional credit market can partly replace credit creation function of traditional credit market, and increase the supply of credit. China's monetary policy is mainly based on quantitative control for a long time. The central bank acts on the commercial banking system by adjusting the base currency and monetary multiplier to realize the regulation of credit and money supply. The absence of shadow credit market supervision making central bank can't adjust monetary multiplier by adjusting the reserve requirements, bank saving deposits is transferred to shadow credit market in various forms, financial disintermediation happens, internal deposits of commercial banks decline, these all lead to the monetary multiplier amplification and increase money supply.

China's monetary policy transmission mainly relies on credit channel and interest rate channel. From the perspective of credit transmission mechanism, shadow credit market is mostly credit chain business model and beyond the central bank's regulation. During the economic boom, the scale of shadow credit market expand excessively, during the economic recession, the scale excessive contraction, leading to the deviation of money supply and weakening the effect of central bank's monetary control. From the point of interest rate channel, the shadow credit market interest rate is higher than the general interest rate, more able to reflect the supply and demand of funds in the credit market. Thus, the existence of shadow credit market may lead to the restriction of interest rate adjustment function and is not conductive to the transmission of monetary policy, having a negative impact on the effects of monetary policy.

\section{Econometric model setting}

\subsection{Variable Selection}

In this paper, we will study the influence of the shadow credit market on China's national economic growth, price level and monetary policy. Select the following indicators.

Economic growth: Since 2004, China's National Bureau of Statistics no longer publish monthly data. Therefore this article use "quarterly GDP data/ quarterly industrial added value data=corresponding monthly GDP data/ corresponding monthly industrial added value data", convert quarterly GDP to monthly GDP data, we use month-on-month GDP growth rate RGDP as the indicator.

Price level: in this paper, use month-on-month CPI growth rate RCPI to measure the changes in the price level.

Money supply: the variable on behalf of the money supply is mainly M0, M1 and M2, according to the division of 
China's money supply, narrow money supply can more reflect the changes of residents and enterprises tightness of money. We choose month-on-month M1 growth rate RM1 as the indicator.

The scale of shadow credit market: according to the different participants, we divide shadow credit market to the dealer, formal financial institution and private lending credit market. We sum entrusted loans, trust loans and no discount bills to estimate formal financial institution credit market. The estimation of private lending credit market is the annual data by using the method of non-observed finance, then convert annual data to monthly data according to monthly GDP and annual GDP ratio. Use month-on-month growth rate of three types of shadow credit market (RTSM、RFSM、RPSM) to conduct empirical study.

In this paper, the data source is Shanghai clearing house, China Central Depository and Clearing Corporation, wind database and national statistical yearbook, all the data are based on monthly data, the time span is from January 2006 to December 2014.

\subsection{Model selection}

In the analysis of the dynamic relationship between economic variables, VAR model has been widely used, it takes each variable as the lag period of all endogenous variables in the system to construct model. VAR model is often used to forecast the interconnected time series systems and analysis the influence of random disturbance on variables, so as to reveal the effect of economic shock on economic variables. In this paper, we study the impact of shadow credit market on economic growth, price level and monetary policy, and research the mutual influence among them. Therefore, we use VAR model to analyze the macroeconomic effect of shadow credit market financing.

\subsection{Stationary test}

Due to many economic variables are non-stationary data, in the process of modeling, we need to test the stability of the economic time series. If all the reciprocal of the roots is less than 1, then the model is stable. Only this model is stable, the conclusion obtained by VAR model is valid. As shown in table 5, all the reciprocal of the roots is less than 1, VAR system satisfies stability condition.

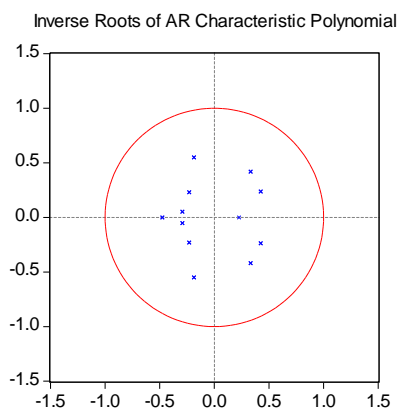

Figure 1. AR diagram

Table 5.AR table

\begin{tabular}{cc} 
Root & Modulus \\
$-0.186084-0.549909 \mathrm{i}$ & 0.580541 \\
$-0.186084+0.549909 \mathrm{i}$ & 0.580541 \\
$0.332446-0.418603 \mathrm{i}$ & 0.534554 \\
$0.332446+0.418603 \mathrm{i}$ & 0.534554 \\
$0.423931-0.236480 \mathrm{i}$ & 0.485428 \\
$0.423931+0.236480 \mathrm{i}$ & 0.485428 \\
-0.475791 & 0.475791 \\
$-0.230284-0.230951 \mathrm{i}$ & 0.326142 \\
$-0.230284+0.230951 \mathrm{i}$ & 0.326142 \\
$-0.292033-0.052941 \mathrm{i}$ & 0.296792 \\
$-0.292033+0.052941 \mathrm{i}$ & 0.296792 \\
0.225655 & 0.225655 \\
\hline
\end{tabular}


4.4 The choice of lag phase in VAR model

Table 6. The choice of lag phase

\begin{tabular}{cclllll}
\hline Lag & LogL & LR & FPE & AIC & SC & HQ \\
0 & 472.7917 & NA & $2.66 \mathrm{E}-12$ & -9.624572 & $-9.46531^{*}$ & $-9.56017^{*}$ \\
1 & 519.6045 & 86.86908 & $2.13 \mathrm{E}-12$ & -9.847516 & -8.732692 & -9.396736 \\
2 & 556.4120 & 63.74901 & $2.12 \mathrm{e}-12^{*}$ & $-9.86416^{*}$ & -7.793778 & -9.027002 \\
3 & 571.7172 & 24.61461 & $3.31 \mathrm{E}-12$ & -9.437468 & -6.411519 & -8.213923 \\
4 & 586.6212 & 22.12555 & $5.33 \mathrm{E}-12$ & -9.002499 & -5.020988 & -7.392571 \\
5 & 610.1736 & 32.05069 & $7.37 \mathrm{E}-12$ & -8.745848 & -3.808773 & -6.749537 \\
6 & 626.0193 & 19.60291 & $1.24 \mathrm{E}-11$ & -8.330295 & -2.437657 & -5.947601 \\
7 & 656.0383 & 33.42323 & $1.63 \mathrm{E}-11$ & -8.206976 & -1.358775 & -5.437899 \\
8 & 680.5412 & 24.25030 & $2.57 \mathrm{E}-11$ & -7.969922 & -0.166159 & -4.814462 \\
9 & 718.1276 & 32.54906 & $3.36 \mathrm{E}-11$ & -8.002632 & 0.756694 & -4.460789 \\
10 & 794.8719 & $56.96484^{*}$ & $2.20 \mathrm{E}-11$ & -8.842720 & 0.872169 & -4.914495 \\
\hline
\end{tabular}

According to the AIC and FPE test, the optimal lagged term is 2 order. Thus, choose the VAR(2) model for subsequent analysis.

\subsection{Granger causality test}

Grange causality test is from the perspective of forecast, define the causal relationship between variables, to test whether variable $\mathrm{X}$ is the Granger cause of the change of variable $\mathrm{Y}$. In the paper, six variables were tested by Granger causality and the results are shown in table 7.

Table 7.Granger causality test

\begin{tabular}{lccc}
\hline \multicolumn{1}{c}{ Null hypothesis } & F & prob & conclusion \\
RTSM is not the cause of RGDP & 1.34604 & 0.5102 & accept \\
RGDP is not the cause of RTSM & 1.87567 & 0.3915 & accept \\
RFSM is not the cause of RGDP & 0.06740 & 0.9669 & accept \\
RGDP is not the cause of RFSM & 23.28998 & 0.0000 & reject \\
RPSM is not the cause of RGDP & 10.56551 & 0.0051 & reject \\
RGDP is not the cause of RPSM & 12.08373 & 0.0024 & reject \\
RTSM is not the cause of RCPI & 3.54152 & 0.1702 & accept \\
RCPI is not the cause of RTSM & 3.32554 & 0.1896 & accept \\
RFSM is not the cause of RCPI & 0.83585 & 0.6584 & accept \\
RCPI is not the cause of RFSM & 0.12757 & 0.9382 & accept \\
RPSM is not the cause of RCPI & 0.21537 & 0.8979 & accept \\
RCPI is not the cause of RPSM & 0.82546 & 0.6618 & accept \\
RTSM is not the cause of RM1 & 4.65956 & 0.0973 & accept \\
RM1 is not the cause of RTSM & 0.00962 & 0.9952 & accept \\
RFSM is not the cause of 起 RM1 & 0.03111 & 0.9846 & 0.5604 \\
RM1 is not the cause of RFSM & 1.15837 & 0.9512 & accept \\
RPSM is not the cause of RM1 & 0.10015 & 0.0001 & accept \\
RM1 is not the cause of RPSM & 19.47690 & accept & reject \\
\hline
\end{tabular}

We can see that under the significant level of 5\%, dealer credit market and economic growth have no causal relationship. Formal financial institution credit market is not the cause of GDP growth, but economic growth is the cause of the formal financial institution credit market. When economic growth, social financing demand is strong, but traditional RMB loan business of commercial banks is regulated by the central bank, credit expansion is restricted, so bank can only through bank financing and other off balance sheet business seeking profit, the scale of formal financial institution expand. Private lending credit market and GDP growth have a cause-effect relationship. On the one hand, economic 
growth will lead to social financing demand increase, private lending as the provider of market liquidity, the scale of credit will also expand. On the other hand, private lending as the main body of credit creation, can ease the problems of financing difficulties of the small and medium-sized enterprises and promote employment, export, technology innovation and economic development.

There is no causal relationship between price and three types of credit market. Therefore, shadow credit market have credit creation function, can increase liquidity supply, and has a certain impact on the price level, but it's not the reason of price level changes. Similarity, the development of shadow credit market is promoted by financial innovation, market competition, bank credit rationing and other external factors, price is not the cause of shadow credit market.

The development of credit market will change the traditional monetary supply model, increase the money supply and weaken the transmission mechanism of monetary policy, thus affecting the effectiveness of monetary policy. But dealer, formal financial institution, private lending credit market is not the cause of money supply. Because when central bank is setting monetary policy to achieve the specific goal, it is unable to observe the scale of shadow credit market effectively, so the development of shadow credit market will affect money supply, but it's not the cause of changes in money supply. The changes of money supply is not the cause of dealer, formal financial institution credit market, but it is the cause of private lending credit market. Private lending credit market is influenced greatly by the credit policy of the traditional commercial bank. When commercial bank implement easy credit policy, money supply and market liquidity is sufficient, small and medium enterprise is more inclined to get loans from commercial banks, because commercial bank capital cost is less than private lending, the scale of private lending credit market will shrink. As a consequence, monetary policy is the cause of private lending credit market, but has no causal relationship with dealer and formal financial institution credit market.

\subsection{Impulse response function}

The basic idea of impulse response is to use time series model to analyze the effects between variables, investigating how the disturbance brought by a single variable spread to other variables, in order to reveal the dynamic relationship between variables.

\subsubsection{The impact of dealer, formal financial institution, private lending shadow credit market on economic growth}

Figure 2 show, when GDP growth rate is positive impacted by the dealer credit market, it decline in the second phase, the third period reach the maximum positive effect and then decline, the fourth period reach the maximum negative effect and then rise, after the fifth period tends to zero. The shock of formal financial institution on GDP growth rate is not obvious, it smoothly tend to zero after fourth period. GDP growth presents a positive effect when it is impacted by the private lending shadow credit market, and in the second phase reach the maximum, then the shock effect decrease rapidly and reach negative maximum in the third phase, after fourth period the shock effect tends to zero. The results of impulse response analysis show that dealer credit market has a negative effect on the economic growth in short-term, but in the long run, positive effect is more obvious. The impact of formal financial institution credit market on economic growth is week. Private lending credit market has the biggest impact on economic growth, in the short term, private lending credit market alleviate the problem of small and medium-sized enterprises financing difficulties, have significant positive impact on economic growth, but after the second period, the shock is negative and tends to zero after fourth period. As a result, the different participants of shadow credit market have different shock effect, the shock of formal financial institution is the weakest and of private lending is the strongest. Shadow credit market have a negative effect on economic growth, and also have a positive effect, is a "double-edged sword" role.
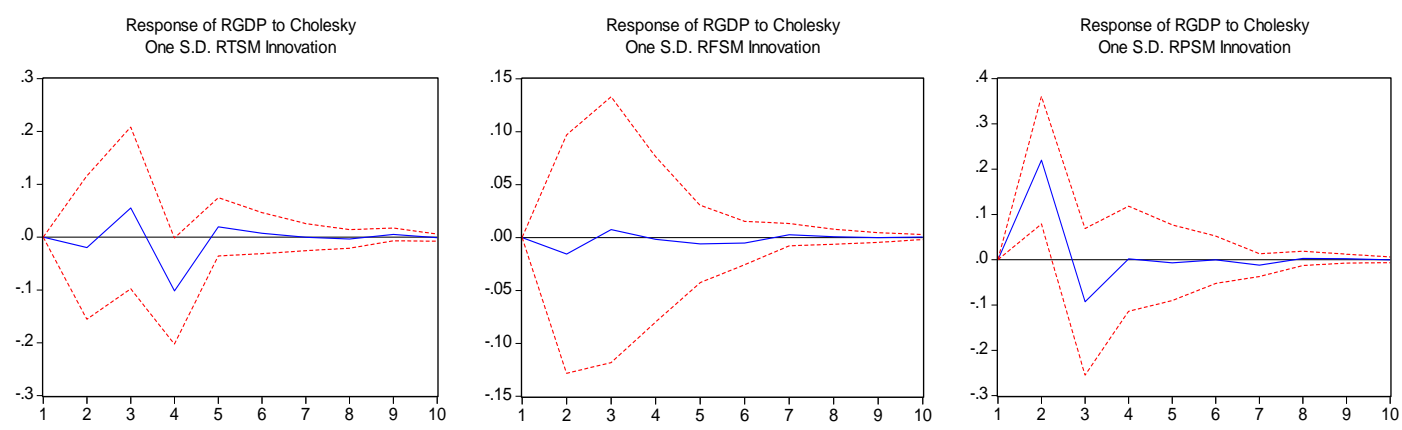

Figure 2. The impact of dealer, formal financial institution, private lending shadow credit market on economic growth 4.6.2 The impact of dealer, formal financial institution, private lending shadow credit market on price level

As shown in figure 3, give dealer credit market positive shock at the initial moment, CPI presents a negative effect and 
reach negative maximum at second period, rise slowly and reach positive maximum at the fourth period, and then slow down to zero, but greater than zero. The shock of formal financial institution on the price level is consistent with private lending credit market. Price level first rise, then decline, after the sixth period tend to zero, and greater than zero. It shows that the impact of three types of shadow credit market on price level is different. But in the long term, they all have positive effect on the price level. Thus, the development of shadow credit market will raise the price level.
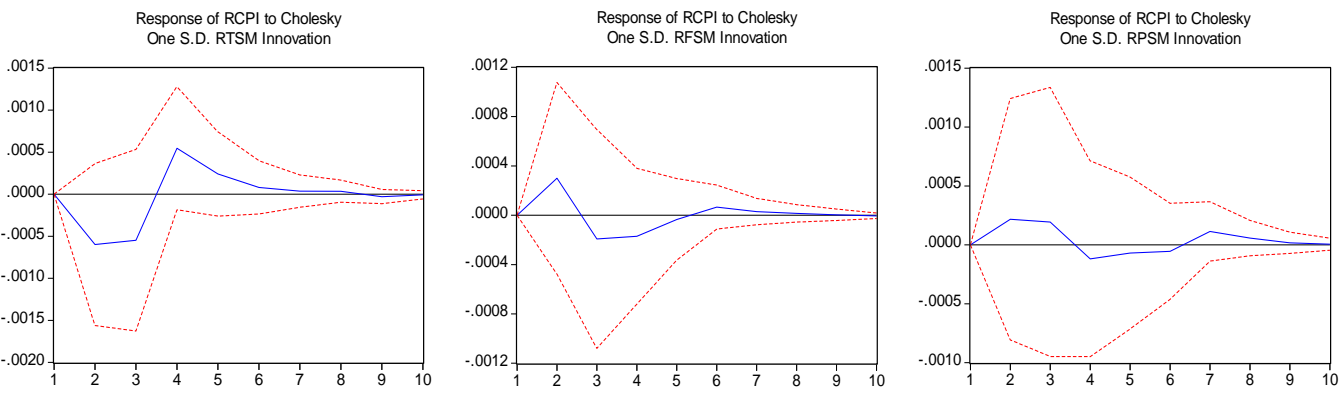

Figure 3. The impact of dealer, formal financial institution, private lending shadow credit market on price level

4.6.3 The impact of dealer, formal financial institution, private lending shadow credit market on money supply

Figure 4 illustrates, give dealer credit market a positive shock, M1 growth rate will rise, at the third period reach positive maximum, then decline and remain volatile, after the seventh period tend to zero. The shock of formal financial institution on M1 growth rate is fluctuating in small range in the first three periods, in the fourth period reach positive maximum, impact effect disappear after seven period. When M1 growth rate is shocked by private lending, in the short time will have a positive effect on the M1 growth rate, after the seventh period tend to zero. Therefore, the development of shadow credit market will result in the increase in money supply.
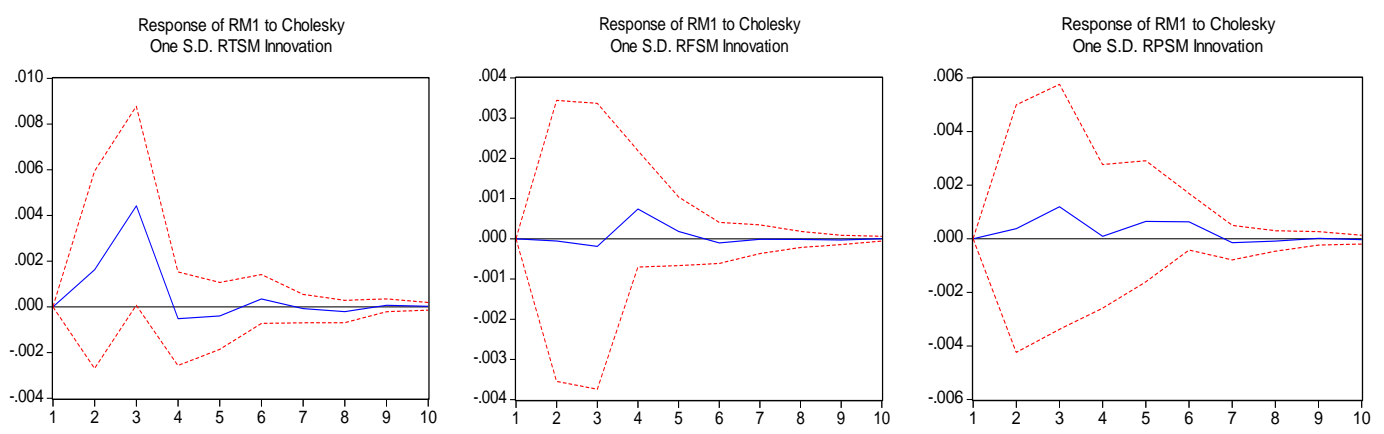

Figure 4. The impact of dealer, formal financial institution, private lending shadow credit market on money supply 4.7 Variance decomposition analysis

Variance decomposition analysis is based on the analysis of the contribution of each structure variable on the endogenous changes, to further evaluate the importance of different structural impact. The article selects several important variables to undergo variance decomposition and set the lag order to 10.

4.7.1 Variance decomposition of economic growth (RGDP)

As can be seen from the table 8 , the effect of dealer, formal financial institution, private lending credit market on the GDP growth rate show an increasing trend. The effect of dealer credit market on GDP growth rate achieve stability after the fifth period, is $2.05 \%$.The effect of formal financial institution is the weakest, stabilize at around $0.0539 \%$ after the sixth period. The effect of private lending credit market is the largest, stabilize at $8.24 \%$ from the fourth period. The contribution of monetary policy and price level on the GDP growth respectively stabilize at $17.07 \%$ and $4.12 \%$ after the seventh period. Therefore, the development of shadow credit market indeed plays a promoted effect on economic growth and private lending credit market has the greatest impact on GDP growth. 
Table 8. Variance decomposition of RGDP

\begin{tabular}{llllllll}
\hline Lag & error & \multicolumn{1}{c}{ RGDP } & RCPI & \multicolumn{1}{c}{ RM1 } & RTSM & RFSM & RPSM \\
1 & 0.671226 & 100 & 0.00000 & 0.00000 & 0.00000 & 0.00000 & 0.00000 \\
2 & 0.808317 & 72.31306 & 4.224499 & 15.96513 & 0.060148 & 0.037412 & 7.399752 \\
3 & 0.823521 & 69.67513 & 4.077079 & 17.29742 & 0.507904 & 0.044212 & 8.398248 \\
4 & 0.830662 & 68.56342 & 4.048536 & 17.08761 & 2.001449 & 0.043858 & 8.255120 \\
5 & 0.831465 & 68.48907 & 4.101470 & 17.06187 & 2.052765 & 0.049015 & 8.245811 \\
6 & 0.832281 & 68.51076 & 4.116339 & 17.03371 & 2.056622 & 0.052910 & 8.229663 \\
7 & 0.832677 & 68.45823 & 4.119923 & 17.07074 & 2.054670 & 0.053870 & 8.242565 \\
8 & 0.832754 & 68.44805 & 4.120210 & 17.07939 & 2.056115 & 0.053927 & 8.242311 \\
9 & 0.832777 & 68.44421 & 4.120781 & 17.07886 & 2.059622 & 0.053925 & 8.242607 \\
10 & 0.832781 & 68.44381 & 4.120912 & 17.07903 & 2.059756 & 0.053950 & 8.242546 \\
\hline
\end{tabular}

4.7.2 Variance decomposition of price level (RGPI)

Table 9 shows that shadow credit market has certain contribution on the price growth rate, but contribution is not high. The influence of dealer credit market on the price growth rate stabilize at $2.7 \%$ after the sixth period. The contribution of formal financial institution and private lending credit market show an increasing trend, and contribution rate is respectively $0.429 \%$ and $0.32 \%$ after the seventh period. The contribution rate of money supply on price level is the biggest and have obvious lag effects, in the first period, it has no influence, after the third period is remained at $26.4 \%$. The impact of economic on price level stabilize at $3.67 \%$ after the sixth period. Thus, the scale of shadow credit market has certain influence on the price level, but the impact is low. The price level is mainly explained by the change of money supply.

Table 9.Variance decomposition of RCPI

\begin{tabular}{lllllrrr}
\hline lag & error & RGDP & \multicolumn{1}{l}{ RCPI } & \multicolumn{1}{c}{ RM1 } & \multicolumn{1}{l}{ RTSM } & \multicolumn{1}{l}{ RFSM } & \multicolumn{1}{l}{ RPSM } \\
1 & 0.004993 & 1.787146 & 98.21285 & 0.00000 & 0.00000 & 0.00000 & 0.00000 \\
2 & 0.005770 & 1.462432 & 75.03851 & 22.01061 & 1.076708 & 0.270058 & 0.141679 \\
3 & 0.006070 & 3.275380 & 67.95088 & 26.41321 & 1.785280 & 0.344750 & 0.230498 \\
4 & 0.006124 & 3.392379 & 66.82558 & 26.54984 & 2.552157 & 0.416306 & 0.263737 \\
5 & 0.006145 & 3.514222 & 66.65454 & 26.45188 & 2.688125 & 0.416579 & 0.274650 \\
6 & 0.006151 & 3.664593 & 66.52754 & 26.39859 & 2.700073 & 0.427183 & 0.282019 \\
7 & 0.006157 & 3.674235 & 66.43115 & 26.45078 & 2.699097 & 0.428660 & 0.316072 \\
8 & 0.006157 & 3.673988 & 66.42301 & 26.44725 & 2.701887 & 0.429154 & 0.324705 \\
9 & 0.006157 & 3.673878 & 66.42086 & 26.44656 & 2.704042 & 0.429170 & 0.325488 \\
10 & 0.006157 & 3.673865 & 66.42070 & 26.44646 & 2.704163 & 0.429239 & 0.325570 \\
\hline
\end{tabular}

4.7.3 Variance decomposition of money supply (RM1)

As can be seen from table 10, the influence of dealer credit market on M1 growth rate begin apparently from the third period, after the third period, the contribution rate remain at around $4 \%$. The impact of formal financial institution on M1 growth rate is weak in the first three period, in the long run, the effect is at around $0.11 \%$. The impact of private lending credit market on M1 growth rate is weak in the first two period, the contribution rate rise to $0.279 \%$ from the third period and have a trend of increase along with time, in the tenth period the effect is about $0.425 \%$. Therefore, the effect of three types of credit market all have obvious lag effect on the money supply, and show an increasing trend. 
Table 10. Variance decomposition of RM1

\begin{tabular}{llllllll}
\hline lag & error & RGDP & RCPI & RM1 & RTSM & RFSM & RPSM \\
1 & 0.022515 & 0.199788 & 6.538660 & 93.26155 & 0.000000 & 0.000000 & 0.000000 \\
2 & 0.023129 & 0.460595 & 6.303353 & 92.71378 & 0.495456 & 0.000564 & 0.026252 \\
3 & 0.023640 & 0.623948 & 6.072392 & 89.04631 & 3.971820 & 0.006961 & 0.278565 \\
4 & 0.023698 & 0.814023 & 6.107923 & 88.69485 & 4.000072 & 0.104579 & 0.278554 \\
5 & 0.023775 & 1.053542 & 6.202657 & 88.28130 & 4.001912 & 0.109820 & 0.350767 \\
6 & 0.023800 & 1.082253 & 6.215220 & 88.15604 & 4.014868 & 0.111488 & 0.420126 \\
7 & 0.023806 & 1.088966 & 6.219243 & 88.14275 & 4.013791 & 0.111459 & 0.423787 \\
8 & 0.023807 & 1.090085 & 6.218979 & 88.13367 & 4.020680 & 0.111501 & 0.425087 \\
9 & 0.023808 & 1.090195 & 6.218929 & 88.13271 & 4.021397 & 0.111677 & 0.425096 \\
10 & 0.023808 & 1.090553 & 6.219177 & 88.13179 & 4.021473 & 0.111675 & 0.425331 \\
\hline
\end{tabular}

4.7.4 Variance decomposition of dealer (RTSM), formal financial institution (RFSM), private lending (RPSM) credit market

From the table 11 dealer credit market variance decomposition can be seen, the effect of economic growth on dealer credit market have the obvious time lag effect, the impact in the first two periods are $0.1344 \%$ and $0.3906 \%$ respectively, and rise rapidly to $8.31 \%$ in the third period, then stabilize at $8 \%$. The impact of price on dealer credit market show a slow upward trend, and stabilize at $4.89 \%$ after the fourth period. The scale of formal financial institution and private lending will also affect the scale of dealer credit market, and after the fourth period, the contribution rate are at around $1.65 \%$ and $5.03 \%$ respectively.

Table 11.Variance decomposition of RTSM

\begin{tabular}{llllllll}
\hline lag & error & RGDP & RCPI & RM1 & RTSM & RFSM & \multicolumn{2}{l}{ RPSM } \\
1 & 0.047617 & 0.134377 & 1.634087 & 0.178913 & 98.05262 & 0.000000 & 0.00000 \\
2 & 0.048942 & 0.390561 & 3.060295 & 0.170084 & 93.12628 & 1.467348 & 1.785432 \\
3 & 0.052269 & 8.318238 & 4.450042 & 0.924120 & 81.69278 & 1.754846 & 2.859971 \\
4 & 0.053759 & 8.000040 & 4.895349 & 3.073342 & 77.32894 & 1.659714 & 5.042610 \\
5 & 0.053844 & 8.019359 & 4.883527 & 3.311912 & 77.09742 & 1.654648 & 5.033139 \\
6 & 0.053886 & 8.006931 & 4.889932 & 3.312723 & 77.10716 & 1.653733 & 5.029516 \\
7 & 0.053891 & 8.005821 & 4.889735 & 3.319280 & 77.09897 & 1.656942 & 5.029248 \\
8 & 0.053895 & 8.012492 & 4.893627 & 3.318733 & 77.08666 & 1.656864 & 5.031624 \\
9 & 0.053897 & 8.013528 & 4.893820 & 3.320290 & 77.08139 & 1.656888 & 5.034085 \\
10 & 0.053898 & 8.013755 & 4.894192 & 3.321441 & 77.07966 & 1.656857 & 5.034091 \\
\hline
\end{tabular}

Table12.Variance decomposition of RFSM

\begin{tabular}{llllllll}
\hline lag & Error & RGDP & RCPI & RM1 & RTSM & RFSM & RPSM \\
1 & 2.225729 & 0.758871 & 0.379184 & 0.022677 & 1.270907 & 97.56836 & 0.000000 \\
2 & 2.242641 & 1.112961 & 0.449416 & 0.023754 & 2.129235 & 96.23067 & 0.053963 \\
3 & 2.549831 & 1.002274 & 0.558994 & 1.538219 & 2.849108 & 74.45030 & 19.60111 \\
4 & 2.563814 & 0.991624 & 0.686192 & 1.609721 & 3.683624 & 73.64086 & 19.38798 \\
5 & 2.571016 & 0.987184 & 0.760091 & 1.965035 & 3.747539 & 73.23100 & 19.30915 \\
6 & 2.572999 & 1.087638 & 0.770204 & 2.000737 & 3.743121 & 73.11885 & 19.27945 \\
7 & 2.573855 & 1.096646 & 0.771008 & 2.045237 & 3.749571 & 73.07066 & 19.26687 \\
8 & 2.574010 & 1.096623 & 0.770930 & 2.051567 & 3.750666 & 73.06195 & 19.26827 \\
9 & 2.574069 & 1.096827 & 0.770970 & 2.051616 & 3.753718 & 73.05865 & 19.26822 \\
10 & 2.574076 & 1.096920 & 0.770966 & 2.051721 & 3.753770 & 73.05828 & 19.26835 \\
\hline
\end{tabular}


Table 13.Variance decomposition of RPSM

\begin{tabular}{llllllll}
\hline lag & error & RGDP & RCPI & RM1 & RTSM & RFSM & RPSM \\
1 & 0.676287 & 96.75686 & 0.063155 & 0.017825 & 0.111745 & 0.005302 & 3.045110 \\
2 & 0.810073 & 70.88948 & 3.625286 & 16.12645 & 0.086370 & 0.052954 & 9.219462 \\
3 & 0.823270 & 68.63575 & 3.561596 & 17.13536 & 0.444880 & 0.055067 & 10.16734 \\
4 & 0.830027 & 67.54577 & 3.536475 & 16.91322 & 1.947812 & 0.054184 & 10.00254 \\
5 & 0.830754 & 67.47620 & 3.602008 & 16.88364 & 1.989161 & 0.059648 & 9.989342 \\
6 & 0.831548 & 67.50371 & 3.616476 & 16.85393 & 1.992039 & 0.063420 & 9.970431 \\
7 & 0.831960 & 67.44857 & 3.620581 & 16.89298 & 1.990618 & 0.064276 & 9.982978 \\
8 & 0.832030 & 67.43924 & 3.621084 & 16.90113 & 1.991935 & 0.064293 & 9.982318 \\
9 & 0.832053 & 67.43572 & 3.621482 & 16.90055 & 1.995590 & 0.064292 & 9.982370 \\
10 & 0.832057 & 67.43521 & 3.621652 & 16.90079 & 1.995727 & 0.064322 & 9.982296 \\
\hline
\end{tabular}

Table 12 shows that economic growth and price level have weak influence on the formal financial institution, private lending credit market has stronger explanation power, and from the beginning of the fourth period, the contribution of private lending credit market on the formal financial institution is about $19.2 \%$.

Table 13 shows that GDP growth rate and M1 growth rate have greater contribution on the scale of private lending credit market. The effect of economic growth on the private lending credit market has a declining trend year by year, the contribution of first period is $96.757 \%$, then decrease slightly and contribution rate remain at around $67.5 \%$ after the fourth period. Price level also have certain effect on the private lending credit market, and remain at around 3.60\% after the second period. The impact of M1 on private lending credit market at the first period is $0.0178 \%$ and after the fourth period is about $16.9 \%$. As a result, private lending market is influenced by economic growth mostly, dealer credit market secondly, and formal financial institution credit market is almost not affected by economic growth. The reason is economic growth will lead to social financing demand increase, but the traditional institution have liquidity limit, private lending expand credit scale at the situation of strong demand for investment and financing, therefore, economic growth has the greatest effect on the private lending credit market, the least influence on the formal financial institution. Price level has a certain contribution on the dealer and private lending shadow credit market, but almost no effect on the formal financial institution credit market. M1 growth rate has the largest influence on the private lending credit market, stabilize at the fourth period, is about $16.9 \%$, but has weak effect on the dealer and formal financial institution credit market.

\section{Conclusions and Policy Recommendations}

This paper firstly define the shadow credit market, divide shadow credit market into the dealer, formal financial institution, private lending credit market according to the different participants, and estimate the scale of three types of shadow credit market respectively. Based on the monthly data from year 2006 to 2014, through constructing VAR model, using Granger Cause tests, impulse response analysis and variance decomposition to study the macroeconomic effects of credit shadow credit market financing, we draw the following conclusions:

First, shadow credit market as the supplement of the traditional credit market, providing liquidity to the market, can effectively alleviate the problems of capital chain rupture in small and medium sized enterprises. The development of shadow credit market can also promote the financing demand of real economy being satisfied, and stimulate economic growth. But the shadow credit market lack of insurance mechanism, have poor capacity to resist risks, which lead to the vulnerability of financial system and is not conductive to the steady growth of macro economy.

Second, the shadow credit market will also impact the monetary policy and price level. Shadow credit market has changed the traditional money supply model, increasing the money supply directly. The development of shadow credit market has also changed the traditional transmission mechanism of credit and interest rate, affecting the effectiveness of monetary policy and even increasing the difficulty of monetary policy regulation mechanism of the central bank. Price level is mainly affected by the changes of money supply and credit scale, shadow credit market inject liquidity into financial market, expanding the money supply and causing certain disturbance to the price level.

Third, economic growth and monetary policy will have obvious effect on the development of shadow credit market. The credit creation function of shadow credit market can alleviate the problems of small and medium-sized financing difficulties and promote economy growth. Meanwhile, the rapid economic growth will increase the financing needs of small and medium-sized enterprises, but subject to the bank credit controls, the scale of entrusted loans, trust loans, private lending will also expand. 
The development of shadow credit market in china is still in the embryonic stage. The regulator authorities should maintain an objective attitude toward the development of shadow credit market, and improve the regulatory environment, strengthen the supervision. Meanwhile, we also need to understand the relationship between shadow credit market and economic growth, price level, monetary supply, better play the resource allocation function of shadow credit market, and strengthen the effectiveness of monetary policy, making the macroeconomic steady growth.

\section{References}

Andrew, S. (2011). The Erosion of U.S. Monetary Policy Management Under Shadow Banking[R].Thailand: International Conference on Business and Information.

Gennaioli, N., Shleifer, A., \& Vishny, R. W., (2011). A Model of shadow banking. Nation bureau of economic research Working paper, 17115. http://www. nber.org/ papers/w17115. http://dx.doi.org/10.3386/w17115

Gertler, M., \& Kiyotaki, N. (2010). Financial Intermediation and Credit Policy in Business Cycle Analysis. Handbook of Monetary Economics, North Holland Publish Press, 547-599. http://dx.doi.org/10.1016/b978-0-444-53238-1.00011-9

$\mathrm{Li}$, J. J. (2008). Non-observed finance and economic operation [M].Beijing, China Financial Publishing House.

Li, J. J., \& Hu, F. Y. (2013). Financing structure of small and medium-sized enterprises, financing cost and the development of shadow credit market [J]. Macroeconomic research, 5.

Liu, R. M., \& Jiang, Y. Research on the impact of shadow banking on China's macroeconomic operation [J]. Price theory and practice, 9.

Pei, P., \&Yin, W. (2014). The credit creation and scale measurement of China's banking [J]. Economic management, 3.

Rydstrom, R. I. (2007). Coping with the National Mortgage Meltdown and the Collapse of the Shadow Banking System [J].USA Today New York, 2007

Shen, Y., \& Xie, K. F. (2013).The development of shadow banking and China's economic growth [J]. Financial Forum, 3, 9-14.

Wang, Z. W. (2010).The influence of shadow banking system on China's money supply [J]. China Finance, 23.

Zhang, S. Q., Zhang, Q. C., \& Gui, Y. (2013).The study of shadow banking size estimation and supervision [J]. International business, 5, 92-101.

\section{(c) $\mathbf{E Y}$}

This work is licensed under a Creative Commons Attribution 3.0 License. 